This is the accepted manuscript of an article published by Oxford University Press in The Gerontologist on December 15, 2020, available online:

https://doi.org/10.1093/geront/gnaa206

\title{
Continuing to participate in the dance of life as oneself: The lived experience of meaning in life for older adults with Alzheimer's disease
}

Laura Dewitte, $\mathrm{PhD}^{1, *}$, Els van Wijngaarden, $\mathrm{PhD}^{2}$, Tine Schellekens, $\mathrm{MSc}^{1}$, Mathieu Vandenbulcke, $\mathrm{PhD}^{3}, \&$ Jessie Dezutter, $\mathrm{PhD}^{1}$

1. Faculty of Psychology and Educational Sciences, KU Leuven, Leuven, Belgium

2. University of Humanistic Studies, Utrecht, The Netherlands

3. University Psychiatric Centre, KU Leuven, Leuven, Belgium

*Address correspondence to: Laura Dewitte, PhD, Faculty of Psychology and Educational Sciences, KU Leuven, Tiensestraat 102 - Box 3717, 3000 Leuven, Belgium. E-mail: laura.dewitte@kuleuven.be 


\section{Conflict of Interest}

The authors report no conflict of interest.

\section{Funding}

This work was supported by the Research Foundation Flanders (grant number 1109417N to L.D.). 


\begin{abstract}
Background and Objectives: Meaning in life is an important aspect of positive psychological functioning for older adults. Limited work suggests the relevance of the experience of meaning for people with dementia, but research into this experience from their personal perspective is lacking. The current study provides an in-depth investigation of the lived experience of meaning in life for older adults with Alzheimer's disease.
\end{abstract}

Research Design and Methods: The study was conducted following the phenomenological reflective lifeworld approach. In-depth interviews were conducted with sixteen older adults $(+65)$ with Alzheimer's disease living either at home or in a nursing home in Belgium. Dataanalysis was an iterative process aimed at illuminating the constituents and essence of the phenomenon.

Results: The essence of the experience of meaning in life for participants was understood as 'continuing to participate in the dance of life as oneself.' This experience was further clarified in four closely intertwined constituents: (1) feeling connected and involved, (2) continuing everyday life as oneself, (3) calmly surrendering and letting go, and (4) desiring freedom, growth, and invigoration.

Discussion and Implications: Our findings contribute to a deeper understanding of meaning in life as experienced by older adults with Alzheimer's disease themselves. They emphasize the relevance of the concept for psychological dementia research and offer original insight for the inclusion of meaning in life as an important aspect of holistic dementia care.

Keywords: Reflective lifeworld approach, Person-centered care, Dementia, Psychological well-being, Positive psychology 


\section{Introduction}

For a long time, dementia research and care was dominated by a biomedical paradigm that prioritized diagnosis, pharmacological treatment, and physical needs (Beard et al., 2009; Beuscher \& Grando, 2009; Lyman, 1989). Since the 1990s, however, a growing number of researchers and practitioners called attention to the subjective experiences of people with dementia and advocated for a person-centered approach that acknowledges their personhood, psychosocial needs, and possibilities (e.g., Clare, 2002; Cotrell \& Schulz, 1993; Kitwood, 1997). Accordingly, the last three decades have seen a considerable increase in literature that includes the personal voices of people with dementia (e.g., Beard, 2016; Clare et al., 2008), and it is now a widely accepted notion that supporting a good life with dementia requires attending to physical, psychological, and socio-cultural aspects of life (Edvardsson et al., 2008; O’Connor et al., 2007).

Though an encouraging trend, the influence of the deficit-focused biomedical paradigm remains noticeable. It is for example a common assumption that the alleviation of psychological distress in dementia equals an increase in well-being, while from a positive psychological perspective, these are two different dimensions (Stoner et al., 2017). Accordingly, scholars have recently called for more explicit consideration of positive narratives towards dementia (Harris \& Keady, 2008; Lin \& Lewis, 2015; Wolverson et al., 2016) and for the inclusion of a positive psychological approach in dementia research, focusing on strengths and abilities such as humor, wisdom, growth, and meaning (Clarke \& Wolverson, 2016).

The focus of the current article is on this latter concept: meaning in life. The subjective experience of meaning in life has received growing attention within contemporary positive psychology and is currently conceptualized as existing of three components: a sense that life is (a) comprehensible and makes sense (coherence), (b) directed by valued life aims 
(purpose), and (c) valuable and worth living (significance) (Martela \& Steger, 2016). This sense of meaning can be derived from different sources of meaning — the personally relevant life domains that make life meaningful, such as family, work, leisure activities, education, material possessions, religion, etc. (Steger, 2018). Studies have demonstrated that the experience of meaning in life is positively associated with a range of physical and psychological outcomes across many populations, including older adults (e.g., Steger, 2009; Steptoe \& Fancourt, 2019). Investigations on meaning in life for people with dementia have been scarce but the limited quantitative work available suggests that adults with Alzheimer's disease who experience higher meaning in life also have less depressive symptoms and more life satisfaction, pointing to the importance of the experience (Dewitte, Vandenbulcke, et al., 2019). There is, however, very little insight into how older adults with dementia understand this experience of meaning. While not the explicit focus, the topic of meaning did appear as an important theme in some qualitative studies that focused on living and coping with dementia. Some early seminal works for example described how dementia may challenge and threaten meaning in life (Bender \& Cheston, 1997; Holst \& Hallberg, 2003). Other studies have suggested that meaning can also be preserved, and these have emphasized the importance of both continuing life as before and adapting to new challenges (Kontos, 2004; Menne et al., 2002; Robertson, 2014; Steeman et al., 2013; Westius et al., 2010). Similarly, Phinney (2011) described narratives referring to on the one hand finding meaning in the same things as before and on the other hand finding meaning in new ways. As an exception, this study did examine explicitly how people with dementia understand their lives as meaningful, but this was done by re-analyzing existing interview data that was again collected with a focus on how people with dementia perceived and coped with their condition. 


\section{Present study}

To further the work on meaning in life as an important aspect of the psychological functioning of people with dementia, an understanding of their insider perspective on meaning is necessary. Such insights are not only relevant for dementia research but have important implications for practice. Care organizations and practitioners increasingly acknowledge the importance of attending to meaning as a crucial dimension of holistic person-centered policy and care. However, the limited available work on meaning in dementia often approaches the theme from a spiritual-religious angle (e.g., MacKinlay \& Trevitt, 2010; van der Steen et al., 2014) whereas meaning is not only relevant for religious/spiritual individuals but a fundamental human concern (Frankl, 1984; Yalom, 1980). A holistic care approach thus necessitates attention for the need for meaning of every person, including those with dementia (Dezutter et al., 2016). The present study therefore aimed to provide an in-depth investigation of what meaning in life means in the everyday life of people with dementia.

\section{Method}

\section{Reflective lifeworld approach}

We used the reflective lifeworld approach (RLA) (Dahlberg et al., 2008), a qualitative approach that emphasizes giving voice to participants by focusing on their personal lived experience. Grounded in $20^{\text {th }}$ century phenomenological philosophy, RLA aims to uncover the 'constituents' and 'essence' of the phenomenon. The constituents are the building blocks of the experience and the essence is the connecting thread running through all constituents, the leitmotiv that connects them into the whole lived experience (van Wijngaarden et al., 2015). RLA aims to capture the essential characteristics of the phenomenon, but this essence is not understood as an unchangeable categorization but as an open description subject to change depending on the specific context (Dahlberg et al., 2008). In the current study, we 
aimed to illuminate the phenomenon of meaning in life as experienced by older adults with Alzheimer's disease living in Belgium.

Central to RLA is that the phenomenon is not approached from an existing theoretical framework but from a first-person perspective, and not described in scholarly terminology but in concrete and experiential terms. In this way, the experience is made explicit and becomes tangible and vivid for others. A key condition herein is openness of the researcher to the experience of the participant, driven by the wish to understand the phenomenon in a new way. Such open attitude entails keeping in check ("bridling”) previously held understandings, beliefs, and assumptions, which requires a constant critical, reflective mind-set (Dahlberg et al., 2008).

\section{Participants and data-collection}

Sixteen older adults $(+65)$ from Belgium with a diagnosis of (probable) Alzheimer's disease ( $\mathrm{AD}$; the most common form of dementia) were interviewed. Participants were recruited through different channels (Alzheimer Liga, Leuven University Psychiatric Center, nursing homes and outpatients' clinics) using purposeful heterogeneity sampling (Patton, 2014). Potential participants were proposed by and discussed with professional contacts from these organizations and we included participants with $\mathrm{AD}$ who could provide their view on the phenomenon under study (e.g., had sufficient verbal abilities), while ensuring the sample was heterogeneous with regard to age, sex, and living situation (nursing home or private home).

Table 1 provides an overview of participant characteristics. Besides demographic information, the Mini-mental State Examination (MMSE; Folstein et al., 1975) was administered to assess the general cognitive status of the participants. Scores ranged between 11 and 26, indicating our participants had mild to moderate dementia.

In line with RLA, in-depth interviews were conducted in the living environment of the participant. One participant was interviewed in the day center where he spent most of his 
time. All interviews were conducted by the first author, a clinically trained psychologist who had previous experience working with older adults with dementia, both in clinical and research settings. The interviews were part of a larger longitudinal project for which this group of participants was interviewed on different occasions over two years (https://osf.io/44jqa/). For the current study, the second interview wave was used, as these interviews contained richer data because of greater interviewer experience and a more comfortable setting because of the prior acquaintance (Danby et al., 2011). For the participants living at home, presence of a partner during the interview was left to the choice of the couples, but partners were invited in advance to let their partner with AD take the lead. All partners kept in the background during the interviews, which lasted between 35 minutes and 2 hours 17 minutes. At the start, the interviewer established rapport and made sure the participant felt comfortable and safe. A process consent approach was adopted (Dewing, 2007), which means that initial written consent was re-established verbally throughout the interview, while the interviewer remained attentive to any signs of distress. All interviews started with an inviting open question. In line with RLA, the interviewer did not use a fixed question list but followed the lead of each participant and attenuated her questions to their specific capabilities (see Table 3 for sample questions). Recordings were transcribed verbatim and complemented with field notes which captured the context of the interview (e.g., setting, atmosphere, non-verbal aspects, conversations with partners, etc.). The study protocol was approved by the Social and Societal Ethics Committee of KU Leuven (ID G-201608612).

\section{Data analysis}

Data analysis according to RLA is a dynamic process of moving back and forth between the raw text (343 pages) and coding on different levels of abstraction. The process of current study is summarized in Table 2. All coding was performed using NVivo 12. To ensure rigor and trustworthiness, discussion with colleagues was done throughout the data collection and 
analysis, team meetings and decisions were carefully documented, and a reflexive journal was kept. This way, we made efforts to make explicit and bridle our pre-existing understanding of the phenomenon, which was important given the extensive previous experience with the meaning in life literature of some of the authors. In addition, we recognized the influence of our beliefs and values as researchers on the research process, such as our personal standpoint that people with dementia can communicate about their experiences and that a meaningful life with dementia is possible. This process of moving back and forth between researcher subjectivity and objectivity (Dahlberg \& Dahlberg, 2020) was facilitated and enriched by the composition of the research team, which consisted of researchers with different backgrounds, including two without expertise in meaning in life theory.

In what follows, we first describe the constituents of the experience of meaning in life for older adults with $\mathrm{AD}$, followed by the essence that ran through the constituents. While the constituents are listed separately, they are closely intertwined, as described in the text and visually depicted in Figure 1. Taken together, the essence and constituents give a tangible description of what experiencing meaning in life is like for older adults living with AD.

\section{Results}

\section{Constituents}

\section{Feeling connected and involved}

For all participants, feeling connected was central to the experience of meaning. Most often, they expressed the importance of connecting and being in close contact with others. Being and feeling together was of central importance and often contrasted with being alone, which many expressed as a dreadful, sometimes even unbearable thought. Helen, who lives with her husband said: 
Dear Lord, if we would lose each other now. I wouldn't be able to stay here in this

house alone. (...) That just wouldn't work. I'm in this big house, who should I talk to?

To the cupboard? (...) As long as you're together, there is always something.

Participants discussed the experience of connecting in a reciprocal bond, sharing thoughts and feelings with others. Here, a tension also emerged, especially for participants more aware of their cognitive decline, who expressed a nagging fear of losing the ability to truly connect with others. Some mentioned not being able to recognize their own children as the ultimate fatality.

Almost all nursing homes residents expressed the value of friendship with fellow residents; of being able to enjoy things together and talk about life experiences with others who have gone through similar things. For most participants, spouses/partners and children were fundamental to life. Alice, who lives in a nursing home, expressed:

You can't express how happy when they visit. (... ) It's a different kind of special feeling. (...) If I would have to see that my children and husband die first, it would be too much for me. (...) If my children and my husband are dead, then I am dead as well. In line, some described that being separated or losing a loved one put meaning under severe pressure. At the same time, participants expressed still feeling connected to the ones they had lost and some expressed finding comfort in talking to them.

The significance of relationships also gained a new dimension, in being cared for and being able to trust on the care of others. Participants expressed feeling loved and valued, noticing that others worried and cared about their well-being. Some nursing home residents expressed appreciation for the efforts and kindness of care staff. Relatedly, some expressed the value of being seen and known by others who recognize your needs (constituent 2), sometimes showing itself in little things on an everyday level. For example, Lucille explained: 
"they know the things you can tolerate the best (...) I can't digest raw vegetables, so they don't give those to me, they give me other things."

However, a few participants also experienced a challenge in receiving care, for example, when they felt it was accompanied by an erosion of other important aspects like their freedom or identity (constituent 2 and 4). Claude recently moved to a nursing home and said:

"They take care of me here. I'm being fed. There are doctors and nurses and all kinds of people who occupy themselves with me. But I'm no longer who I was (...) Try to put yourself in my position. You leave this room, by chance you run into someone in the hallway who says: 'How are you doing?' and 'what did you do yesterday?' and so forth. Very coincidentally, and very friendly. But you're being put under supervision. And you're being put on the same level as people who aren't able to talk anymore. Most participants did not only want to be on the receiving end of love and support, they also wanted to be involved in the lives of those close to them and they still wanted to help out wherever they could. Referring to his participation in the current study, Isaac remarked: “I know I'm also passing on something that others (...) will try to do something positive with. I try to see it as a gift for others who are suffering."

From a broader perspective, participants did not only want to feel connected to others, many also expressed a desire to stay connected to and involved in the world-some more passively, by hearing and reading about the world, others more active, by being able to contribute or create something of value (constituent 4). At the same time, some described a change in this involvement with aging, with less desire to actively influence the course of things, feeling content to observe from the sidelines (constituent 3). However, a few participants also expressed a growing sense of disconnection/detachment from the world surrounding them. 


\section{Continuing everyday life as oneself}

Participants expressed a desire to stay who they are and to retain their individuality, commonly conveying the message that "they've just always been like that." Beatrice talked about the importance of being clean and looking nice: "It's always been important. When I was little, I always was such a proud little thing (...) That's my goal still; clean, neat, put together." Relatedly, they wanted others to see them, accept and value them for who they are. For some, being seen by others also meant being recognized in the losses and suffering they had been through.

Many expressed the wish to continue daily routines, life as it always has been. Underlying this was sometimes the uneasy realization that this might not be possible and that things might change for the worse. Raymond described it this way:

When you're getting old, you don't feel like seeing things change. You much rather want everything to stay as it is (...) But it cannot stay the same of course. Sooner or later the bomb will drop.

A few participants expressed a fear of losing who they are, especially when they thought about other people with dementia in more advanced stages. A couple of participants talked about considering euthanasia when dementia progressed severely, but at the same time they expressed a drive to persevere and live on (constituent 4).

For all participants, the present day often gained its meaning in relation to the past; that is, the present experiences gained significance against the background of the entire life lived. This was exemplified by references to back in the days, important memories (both difficult and joyful), values, and activities that participants carried with them throughout life and remained meaningful up to the present day. For many, the job they had and/or the family they had raised in the past were in the foreground of their mind. Meaningful activities in the present were often framed within memories of the past. For example, Martha talked about 
how much she enjoys walking and reminisced about her travels in the past. Lucille talked about how listening to music reminds her of her dancing days: "I used to enjoy dancing, but I can't do it anymore. (...) Now I like to listen to it, I always have the music on."

\section{Calmly surrendering and letting go}

Participants often talked about taking every day as it comes and surrendering to and surfing the waves of life as they arise, acknowledging that often you can't control the things that happen. They expressed a sense of equanimity, a positive resignation. A part of this experience was being able to accept that some things are irretrievably lost and that some things are not exactly the way they hoped or imagined. This acceptance was reinforced by the decision not to resist or fight the unchangeable, but to let go instead. Lillian reflected on accepting and adjusting to life in the nursing home:

My home is still my home. But I'm more often here than I'm home of course. And in the beginning, that too is difficult. But you have to accept it, because otherwise you just run around feeling like 'ugh'. (...) When you're at home, you can do what you want. We shouldn't complain though. The food and everything. But you do have to adapt a little (...)You have to be able to step over it; you shouldn't linger over it and say: 'oh, I can't do this or I can't do that, or then I can't do-' (...) You have to let it go.

Martha echoed the importance of taking a flexible and accepting attitude, even when life hits you hard:

My husband. He passed away so early. I suffered from that (long silence). Take it as it comes, I say. Nothing to do about it. (...) I take everything as it comes. That's all you can do. (...) One day you feel better than the other (...) But oh well no, I feel good here and I do what I like to do. (...) I just live in the day that is there, I would say. 
Some, like the women quoted above, took a predominantly positive perspective to the experience of adjusting/accepting and talked about how it allowed them to be satisfied in the present day. However, others expressed more ambiguous feelings: sometimes accepting and adjusting is a unpleasant necessity, you don't really have a choice. Lucille said about living separated from her husband:

I already asked the doctor: 'Let me go home, so I can help him.' But I'm not allowed. I have to stay here. Oh well. You have to take it as it is. (...) I don't think about that. Because if I think about before, my younger years, then I'm not happy. And otherwise I am. So I just set aside those thoughts.

Related to the attitude of letting the day take its course (constituent 2), participants conveyed the idea that the normal, simple life as it is, is sufficient; life doesn't have to be extraordinary. For many, the attitude of letting go and surrendering fostered a sense of being content and in peace, which for some was enhanced by being a in a trusted, quiet environment. These different aspects are for example represented in the account of Raymond, who was interviewed in his garden:

I'm satisfied here and I don't have any problems. All my problems stay behind that fence. (...) Things are going well enough. I'm not bored, less than before even. Probably because I resign myself to it more. (...) The world keeps on turning. But me, I don't worry about all that. You see, I'm sitting here. Before I would've said: 'That hedge, it's growing, dammit.' Now on the contrary, I say: 'Hedge, you just grow.'

\section{Desiring freedom, growth, and invigoration}

While participants valued peace and calm, all participants also expressed a simultaneous desire to experience and learn new things. Related to constituent 1 and 2, some participants liked to stay involved and up to date on things that had always been important to them. Raymond, a former teacher, said: 
My ears sharpen when something like that happens in the world. (...) For example

Lombok, everything I can find I have to know about it. I'm still strongly interested in it, no matter how old I am.

For some, the desire for new impressions was less about learning things, but more about enlarging the lifeworld, trying to keep it from shrinking by hearing stories from others or by going new places. It was therefore also central for participants not to feel limited, restricted or confined; but to feel as if they were able to do as they pleased and go where they wanted. For those living at home, there was sometimes the fear of having to go to an institution. However, most of the participants already living in residential care had adjusted well to their situation (constituent 3 ) and exercised their desire for freedom within the boundaries of the setting.

At other times, being able to move freely was not only about being able to go somewhere but also about feeling alive, lively, and young by literally being in motion. Many participants talked about the joy of walking or dancing and some expressed how much they missed riding their bike.

Two participants - one living in a nursing home and one living at home but staying in a day center during the day-however described a feeling of "un-freedom", of being imprisoned, trapped, locked up, which was accompanied by eroded feelings of connection and continuity (constituents 1 and 2). Martin said about his experience of being in the day center: “It's like a prison (...) People I don't know. (...) I look at a newspaper but other than that I don't do anything anymore. Well yes, you're retired, you're supposed to be silent and do nothing."

The desire to feel free and experience new things thus also links back to a desire to be connected to the world (constituent 1). Participants expressed a drive to do something, have a purpose, contribute something valuable. Isaac said: "I try to be positive in all sorts of ways: 
putting things together, painting (...) If you don't have passion, then nothing will work and then you can't be creative. Simple as that." Leon emphasized the importance of doing something useful but also talked about the fear of losing this ability because of his dementia: When something is dirty and you can clean it, than it is useful to me (...) You've achieved something, made something better than it was before (...) If you're not useful anymore, then you're not a human anymore (...) I don't think about it often, but on moments where I don't have much to do, then these thoughts sometimes come up (...) Those are difficult moments.

\section{Essence}

Integrating the four constituents of the phenomenon, the essence of the experience of meaning in life for older adults with Alzheimer's disease is described as continuing to participate in the dance of life as oneself. Participants' stories were characterized by an interplay between reaching out and connecting on the one hand, and letting go, going with the flow on the other hand. Participating in the dance of life this way nourishes a sense of mattering by being able to contribute, by being loved and cared for, by being recognized. Participants expressed the need to continue to play their part and to move through the dance of life to their own rhythm. In the different stories, meaning was experienced as a balance between continuing the familiar, day-to-day movements on the one hand and exploring new avenues on the other hand. Still, a tension often ran through the stories; a nagging worry of losing the ability to participate in the dance of life; losing the ability to connect, be involved, move freely, and stay oneself as a consequence of dementia.

While all participants were able to talk about their experience of meaning, they also showed hesitation and difficulty in finding words to adequately express this multifaceted experience. This shows that, while meaning in life is universal and everyday-like, it is also something subtle and elusive that is hard to bring into words. 


\section{Discussion}

The present study provides in-depth insight into meaning in life as experienced by older adults with Alzheimer's disease. Guided by a phenomenological RLA, we found that the experience of meaning in life could be understood as 'continuing to participate in the dance of life as oneself'. Our findings give scientific support to the importance of including meaning in life into dementia care and policies.

Previous qualitative work that touched upon the topic of meaning in dementia discussed how meaning can be found in a balance between continuation and change (e.g., Menne et al., 2002; Phinney, 2011). Our study corroborates this conclusion, but as the first indepth investigation specifically focused on meaning in life, it offers a richer and more nuanced description of the experience. First, our findings expose the different layers that contribute to a sense of continuity, such as retaining individuality in one's own eyes and the eyes of others, continuing everyday normal life, and involvement in valued interests from the past. Through these different layers, the importance of the past in giving meaning to the present was highlighted. Our findings clearly reflected the phenomenological idea that the past is not an objective time-gone-by but a remembered past which is experienced and shapes what is meaningful in the present (Van den Berg, 1972).

Second, our findings also elucidate that there are different facets to the role of change and adaptation in the experience of meaning. On the one hand, surrendering to changes and letting go of the unchangeable was important — a finding that corroborates previous evidence emphasizing the importance of accepting changes and losses in dementia (e.g., Clare et al., 2008; Holst \& Hallberg, 2003; MacQuarrie, 2005). However, this process of adaption was not experienced as one-sidedly negative and it often supported feelings of peace and contentment, or what Beard (2016) called "serenity" (p. 152). This is in line with a phenomenological perspective on living with illness that acknowledges the positive aspects of managing losses 
(Carel, 2012). However, finding meaning in change was not only a response to challenges; change was also actively pursued, driven by a desire for new experiences and growth, and a continued connection to the world. This aligns with recent phenomenological work showing the importance of learning experiences for vulnerable older adults, which contribute to a sense of being and becoming (individual aspects) and a sense of belonging (social aspects) (Narushima et al., 2018).

In contrast to previous work, participants were not asked about the impact of dementia on their experience of meaning unless they brought it up themselves. By investigating meaning from this open perspective, our findings highlight that the experience of meaning for people with AD is partly influenced by their dementia but not fully determined by it. At the same time, all participants described certain challenges to meaning and some expressed suffering and fear, but the majority expressed at least as much positivity and optimism. In this way, our findings contribute to a balanced view including positive experiences in dementia (Lin \& Lewis, 2015).

While an a-theoretical approach was taken for the analyses, our findings can retrospectively be framed within the three-component theory of meaning in life (Martela \& Steger, 2016). More specifically, coherence was reflected in the need for continuation across past-present-future. Furthermore, coping through acceptance can be seen as an accommodating meaning making process that further sustains this coherence. The importance of a sense of purpose was also reflected in the theme of involvement and the drive to contribute. Significance, finally, was most evident in the emphasis participants placed on being acknowledged, valued, and loved for who they are. Prominent sources of meaning in life were also running through the four constituents, for example, interpersonal relationships, work, personal growth, and society and community (Delle Fave et al., 2013). 
Additionally, current findings can contribute to at least four broader psychological theories. First, self-determination theory discusses the basic needs of relatedness, autonomy, and competence (Ryan \& Deci, 2017). Fulfillment of these needs has been shown to contribute to meaning in life in a general population (Martela et al., 2018). Our findings align with this view and show that for people with dementia as well, these needs are central to the experience of meaning. A sense of relatedness does not only entail connecting with others but also being able to count on them in times of need. In this sense, our findings also align with attachment theory, as they highlighted aspects of being cared for by others who offer safety and predictability, but also of being truly seen and recognized by others who affirm your existence and offer a secure base for exploration and growth (Bowlby, 1988; Dewitte, Granqvist, et al., 2019). The findings also support two other developmental frameworks. According to Socio-Emotional Selectivity Theory (SST; Carstensen et al., 1999), older adults approaching the end of life will prioritize an emotional balance in the present over instrumental goals for the future. Participants' expressions of living day by day in a quiet, content way aligns with this tenet. An accepting and adjusting attitude was deemed vital in attaining this state. This in turn resonates with the theory of selective optimization with compensation (SOC; Baltes \& Baltes, 1990), which describes the importance of optimizing available abilities to compensate for losses in old age.

Some shortcomings of the current study provide input for future research. First, our findings describe the essence of meaning in life for the participants included at the time of the interviews. While we aimed to compose a heterogeneous group, allowing for some extrapolation to others living at home or in nursing homes in Belgium or similar societies, future studies may wish to examine the lived experience of meaning in life for older adults with dementia with different socio-cultural backgrounds (all participant of the current study were white Western Europeans) or different living circumstances (e.g., living alone). Second, 
as the current investigation focused on the experience of people with dementia, the voices of partners or carers were not incorporated. Including these perspectives in future studies can be a valuable complement. Finally, the use of interviews prevented the inclusion of participants with strong verbal difficulties. Other methods using for example art or video work provide options for future studies.

\section{Clinical implications}

Present study provides recommendations for the further development of a meaning dimension within a holistic approach to dementia. Our findings clearly demonstrated that similar circumstances could be experienced and understood totally different by different participants (Carel, 2012). For example, two male nursing home residents talked about the importance of freedom. While they both lived in a closed ward, one of them still experienced his freedom very much, while the other struggled with feeling imprisoned. When listening closely to each story, small nuances that shape the experiences are discovered: not the closed doors are the main issue, but the sense of having to provide justification and feeling belittled - even if care staff means very well. Another participant also described feeling imprisoned, but his account illuminated that this feeling arose predominantly from a sense of detachment of his family, home, and previous occupation (and therefore his own life story). A phenomenological approach allows to bridge the gap between an understanding of objective circumstances and of how these circumstances are experienced (Carel, 2011). Phenomenological tools can help researchers, practitioners, and caregivers gain deeper insight into the experiences of people with dementia and can support people with dementia themselves in reflecting on their experiences (Carel, 2012).

In addition, some more specific strategies for supporting meaning can be suggested. First, our findings re-emphasize the fundamental importance of connectedness with others. Relationship quality with those surrounding people with dementia is a priority for supporting 
meaning in life (Edvardsson et al., 2008; Haugan et al., 2020). Second, our findings endorse initiatives that foster a sense of involvement and contribution, such as volunteering (e.g., George, 2011; Mak, 2011). Importantly, such activities need to be aligned with a person's self-view and interests (e.g., Cohen-Mansfield et al., 2006). Valued activities from the past may provide guidance, but possible new interests should also be explored. Offering people with dementia possibilities and the ability to make an active choice supports a sense of freedom and renders the chosen option more meaningful (Carel, 2012). Next, our findings with regard to the importance of bodily movement (e.g., walking and dancing, constituent 4) demonstrate the grounding of meaning in the body (i.e., embodiment; see Kontos, 2004) and suggest the usefulness of interventions focusing on movement and touch. The latter may be especially valuable in more advanced stages, when verbal communication becomes more difficult (e.g., Simard \& Volicer, 2009). Our findings also invite reflection on the consequences of limiting bodily movement (Carel, 2012). While restrictions are often imposed out of safety considerations, these may not correspond with the priorities of the person with dementia. Finally, our findings resonate with previous work showing the benefits of reminiscence and life story work (e.g., Ching-Teng et al., 2020; MacKinlay \& Trevitt, 2010; Woods et al., 2018). Interventions focusing on meaningful memories and stories may help older adults come to terms with more difficult chapters of their life. 
Baltes, P. B., \& Baltes, M. M. (1990). Psychological perspectives on successful aging: The model of selective optimization with compensation. Successful aging: Perspectives from the behavioral sciences, 1(1), 1-34. https://doi.org/10.1017/CBO9780511665684.003

Beard, R. L. (2016). Living with Alzheimer's: Managing memory loss, identity, and illness. New York University Press.

Beard, R. L., Knauss, J., \& Moyer, D. (2009). Managing disability and enjoying life: How we reframe dementia through personal narratives. Journal of Aging Studies, 23(4), 227235. https://doi.org/10.1016/j.jaging.2008.01.002

Bender, M., \& Cheston, R. (1997). Inhabitants of a lost kingdom: A model of the subjective experiences of dementia. Ageing and Society, 17(5), 513-532. https://doi.org/10.1017/S0144686X97006570

Beuscher, L., \& Grando, V. T. (2009). Challenges in conducting qualitative research with individuals with dementia. Research in gerontological nursing, 2(1), 6-11. https://doi.org/10.3928/19404921-20090101-04

Bowlby, J. (1988). A secure base: Clinical applications of attachment theory. Routledge

Carel, H. (2011). Phenomenology and its application in medicine. Theoretical medicine and bioethics, 32(1), 33-46. https://doi.org/10.1007/s11017-010-9161-x

Carel, H. (2012). Phenomenology as a resource for patients. The Journal of Medicine and Philosophy: A Forum for Bioethics and Philosophy of Medicine, 37(2), 96-113. https://doi.org/10.1093/jmp/jhs008

Carstensen, L. L., Isaacowitz, D. M., \& Charles, S. T. (1999). Taking time seriously: A theory of socioemotional selectivity. American Psychologist, 54(3), 165. https://doi.org/10.1037//0003-066X.54.3.165

Ching-Teng, Y., Ya-Ping, Y., Chia-Ju, L., \& Hsiu-Yueh, L. (2020). Effect of group reminiscence therapy on depression and perceived meaning of life of veterans diagnosed with dementia at veteran homes. Social Work in Health Care, 59(2), 75-90. https://doi.org/10.1080/00981389.2019.1710320

Clare, L. (2002). We'll fight it as long as we can: Coping with the onset of Alzheimer's disease. Aging \& Mental Health, 6(2), 139-148. https://doi.org/10.1080/13607860220126826

Clare, L., Rowlands, J., Bruce, E., Surr, C., \& Downs, M. (2008). The experience of living with dementia in residential care: an interpretative phenomenological analysis. The Gerontologist, 48(6), 711-720. https://doi.org/10.1093/geront/48.6.711

Clarke, C., \& Wolverson, E. (2016). Positive psychology approaches to dementia. Jessica Kingsley Publishers.

Cohen-Mansfield, J., Parpura-Gill, A., \& Golander, H. (2006). Utilization of Self-Identity Roles for Designing Interventions for Persons With Dementia. The Journals of Gerontology: Series B, 61(4), P202-P212. https://doi.org/10.1093/geronb/61.4.P202

Cotrell, V., \& Schulz, R. (1993). The perspective of the patient with alzheimer's disease: A neglected dimension of dementia research. The Gerontologist, 33(2), 205-211. https://doi.org/10.1093/geront/33.2.205

Dahlberg, H., \& Dahlberg, K. (2020). Open and reflective lifeworld research: A third way. Qualitative Inquiry, 26(5), 458-464. https://doi.org/10.1177/1077800419836696

Dahlberg, K., Dahlberg, H., \& Nyström, M. (2008). Reflective lifeworld research (2nd, Ed.). Studentlitteratur, Lund. 
Danby, S., Ewing, L., \& Thorpe, K. (2011). The novice researcher: Interviewing young children. Qualitative Inquiry, 17(1), 74-84. https://doi.org/10.1177/1077800410389754

Delle Fave, A., Brdar, I., Wissing, M. P., \& Vella-Brodrick, D. A. (2013). Sources and motives for personal meaning in adulthood. The Journal of Positive Psychology, 8(6), 517-529. https://doi.org/10.1080/17439760.2013.830761

Dewing, J. (2007). Participatory research: a method for process consent with persons who have dementia. Dementia, 6(1), 11-25. https://doi.org/10.1177/1471301207075625

Dewitte, L., Granqvist, P., \& Dezutter, J. (2019). Meaning through attachment: An integrative framework. Psychological Reports, 122(6), 0033294118799739. https://doi.org/10.1177/0033294118799739

Dewitte, L., Vandenbulcke, M., \& Dezutter, J. (2019). Meaning in life matters for older adults with Alzheimer's disease in residential care: associations with life satisfaction and depressive symptoms. International psychogeriatrics, 1-9. https://doi.org/10.1017/S1041610218002338

Dezutter, J., Offenbaecher, M., Vallejo, M. A., Vanhooren, S., Thauvoye, E., \& Toussaint, L. (2016). Chronic pain care: The importance of a biopsychosocial-existential approach. The International Journal of Psychiatry in Medicine, 51(6), 563-575. https://doi.org/10.1177/0091217417696738

Edvardsson, D., Winblad, B., \& Sandman, P.-O. (2008). Person-centred care of people with severe Alzheimer's disease: current status and ways forward. The Lancet Neurology, 7(4), 362-367. https://doi.org/10.1016/S1474-4422(08)70063-2

Finfgeld-Connett, D. (2014). Use of content analysis to conduct knowledge-building and theory-generating qualitative systematic reviews. Qualitative Research, 14(3), 341352. https://doi.org/10.1177/1468794113481790

Folstein, M. F., Folstein, S. E., \& McHugh, P. R. (1975). Mini-mental state: a practical method for grading the cognitive state of patients for the clinician. Journal of psychiatric research, 12(3), 189-198.

Frankl, V. E. (1984). Man's search for meaning: Revised and updated. Washington Square Press.

George, D. R. (2011). Intergenerational volunteering and quality of life: mixed methods evaluation of a randomized control trial involving persons with mild to moderate dementia. Quality of life Research, 20(7), 987-995. https://doi.org/10.1007/s11136010-9837-8

Harris, P. B., \& Keady, J. (2008). Wisdom, resilience and successful aging: Changing public discourses on living with dementia. https://doi.org/10.1177/1471301207085364

Haugan, G., Kuven, B. M., Eide, W. M., Taasen, S. E., Rinnan, E., Xi Wu, V., Drageset, J., \& André, B. (2020). Nurse-patient interaction and self-transcendence: assets for a meaningful life in nursing home residents? BMC geriatrics, 20(1), 168. https://doi.org/10.1186/s12877-020-01555-2

Holst, G., \& Hallberg, I. R. (2003). Exploring the meaning of everyday life, for those suffering from dementia. American Journal of Alzheimer's Disease \& Other Dementias, 18(6), 359-365. https://doi.org/10.1177/153331750301800605

Kitwood, T. M. (1997). Dementia reconsidered: The person comes first (Vol. 20). Open university press Buckingham.

Kontos, P. C. (2004). Ethnographic reflections on selfhood, embodiment and Alzheimer's disease. Ageing \& Society, 24(6), 829-849. https://doi.org/10.1017/S0144686X04002375 
Lin, S.-Y., \& Lewis, F. M. (2015). Dementia friendly, dementia capable, and dementia positive: concepts to prepare for the future. The Gerontologist, 55(2), 237-244. https://doi.org/10.1093/geront/gnu122

Lyman, K. A. (1989). Bringing the social back in: A critique of the biomedicalization of dementia. The Gerontologist, 29(5), 597-605. https://doi.org/10.1093/geront/29.5.597

MacKinlay, E., \& Trevitt, C. (2010). Living in aged care: Using spiritual reminiscence to enhance meaning in life for those with dementia. International journal of mental health nursing, 19(6), 394-401. https://doi.org/10.1111/j.1447-0349.2010.00684.x

MacQuarrie, C. R. (2005). Experiences in early stage Alzheimer's disease: understanding the paradox of acceptance and denial. Aging \& Mental Health, 9(5), 430-441. https://doi.org/10.1080/13607860500142853

Mak, W. (2011). Self-reported goal pursuit and purpose in life among people with dementia. The Journals of Gerontology: Series B, 66B(2), 177-184. https://doi.org/10.1093/geronb/gbq092

Martela, F., Ryan, R. M., \& Steger, M. F. (2018). Meaningfulness as satisfaction of autonomy, competence, relatedness, and beneficence: Comparing the four satisfactions and positive affect as predictors of meaning in life. Journal of Happiness Studies, 19(5), 1261-1282. https://doi.org/10.1007/s10902-017-9869-7

Martela, F., \& Steger, M. F. (2016). The three meanings of meaning in life: Distinguishing coherence, purpose, and significance. The Journal of Positive Psychology, 11(5), 531545. https://doi.org/10.1080/17439760.2015.1137623

Menne, H. L., Kinney, J. M., \& Morhardt, D. J. (2002). 'Trying to Continue to Do as Much as They Can Do' Theoretical insights regarding continuity and meaning making in the face of dementia. Dementia, 1(3), 367-382. https://doi.org/10.1177/147130120200100308

Narushima, M., Liu, J., \& Diestelkamp, N. (2018). I learn, therefore I am: A phenomenological analysis of meanings of lifelong learning for vulnerable older adults. The Gerontologist, 58(4), 696-705. https://doi.org/10.1093/geront/gnx044

O’Connor, D., Phinney, A., Smith, A., Small, J., Purves, B., Perry, J., Drance, E., Donnelly, M., Chaudhury, H., \& Beattie, L. (2007). Personhood in dementia care: Developing a research agenda for broadening the vision. Dementia, 6(1), 121-142. https://doi.org/10.1177/1471301207075648

Patton, M. Q. (2014). Qualitative research \& evaluation methods: Integrating theory and practice. Sage publications.

Phinney, A. (2011). Horizons of meaning in dementia: Retained and shifting narratives. Journal of Religion, Spirituality \& Aging, 23(3), 254-268. https://doi.org/10.1080/15528030.2011.563210

Robertson, J. M. (2014). Finding meaning in everyday life with dementia: A case study. Dementia, 13(4), 525-543. https://doi.org/10.1177/1471301213479357

Ryan, R. M., \& Deci, E. L. (2017). Self-determination theory: Basic psychological needs in motivation, development, and wellness. Guilford Publications.

Simard, J., \& Volicer, L. (2009). Effects of Namaste Care on Residents Who Do Not Benefit From Usual Activities. American Journal of Alzheimer's Disease \& Other Dementiasr, 25(1), 46-50. https://doi.org/10.1177/1533317509333258

Steeman, E., Tournoy, J., Grypdonck, M., Godderis, J., \& De Casterlé, B. D. (2013). Managing identity in early-stage dementia: maintaining a sense of being valued. Ageing \& Society, 33(2), 216-242. https://doi.org/10.1017/S0144686X11001115 
Steger, M. F. (2009). Meaning in life. In S. J. Lopez \& C. R. Snyder (Eds.), Oxford handbook of positive psychology (pp. 679-687). Oxford University Press.

Steger, M. F. (2018). Meaning in life: A unified model. In C. R. Snyder, S. J. Lopez, L. M. Edwards, \& S. C. Marques (Eds.), Oxford handbook of positive psychology (3rd ed.). Oxford University Press.

Steptoe, A., \& Fancourt, D. (2019). Leading a meaningful life at older ages and its relationship with social engagement, prosperity, health, biology, and time use.

Proceedings of the National Academy of Sciences, 116(4), 1207-1212. https://doi.org/10.1073/pnas.1814723116

Stoner, C. R., Orrell, M., Long, M., Csipke, E., \& Spector, A. (2017). The development and preliminary psychometric properties of two positive psychology outcome measures for people with dementia: the PPOM and the EID-Q. BMC geriatrics, 17(1), 72. https://doi.org/10.1186/s12877-017-0468-6

Van den Berg, J. H. (1972). A different existence: Principles of phenomenological psychopathology. Duquesne University Press.

van der Steen, J. T., Gijsberts, M.-J. H. E., Hertogh, C. M. P. M., \& Deliens, L. (2014). Predictors of spiritual care provision for patients with dementia at the end of life as perceived by physicians: a prospective study. BMC Palliative Care, 13(1), 61. https://doi.org/10.1186/1472-684X-13-61

van Wijngaarden, E., Leget, C., \& Goossensen, A. (2015). Ready to give up on life: The lived experience of elderly people who feel life is completed and no longer worth living. Social Science \& Medicine, 138, 257-264. https://doi.org/10.1016/j.socscimed.2015.05.015

Westius, A., Kallenberg, K., \& Norberg, A. (2010). Views of life and sense of identity in people with Alzheimer's disease. Ageing \& Society, 30(7), 1257-1278. https://doi.org/10.1017/S0144686X10000309

Wolverson, E., Clarke, C., \& Moniz-Cook, E. (2016). Living positively with dementia: a systematic review and synthesis of the qualitative literature. Aging \& Mental Health, 20(7), 676-699. https://doi.org/10.1080/13607863.2015.1052777

Woods, B., O'Philbin, L., Farrell, E. M., Spector, A. E., \& Orrell, M. (2018). Reminiscence therapy for dementia. Cochrane Database of Systematic Reviews(3). https://doi.org/10.1002/14651858.CD001120.pub3

Yalom, I. D. (1980). Existential psychotherapy (Vol. 1). Basic Books New York. 
Table 1. Participant characteristics.

\begin{tabular}{|c|c|c|c|c|c|c|c|}
\hline Pseudonym & Sex & Age & Living situation & Marital state & $\begin{array}{l}\text { Highest education } \\
\text { level }\end{array}$ & Religious affiliation & MMSE $^{a}$ \\
\hline Helen & Woman & 88 & Private home & Married & Higher education & Catholic & 26 \\
\hline Joseph & Man & 68 & Private home & Cohabiting & Higher education & Non-religious & 11 \\
\hline Norman & Man & 83 & Private home & Married & $\begin{array}{l}\text { Higher secondary } \\
\text { education }\end{array}$ & Christian & 12 \\
\hline Mildred & Woman & 88 & Nursing home & Divorced & $\begin{array}{l}\text { Higher secondary } \\
\text { education }\end{array}$ & Catholic & 16 \\
\hline Martha & Woman & 97 & Nursing home & Widowed & $\begin{array}{l}\text { Lower secondary } \\
\text { education }\end{array}$ & Catholic & 22 \\
\hline Isaac & Man & 69 & Private home & Married & Higher education & $\begin{array}{l}\text { Religious without } \\
\text { affiliation to church }\end{array}$ & 20 \\
\hline Lucille & Woman & 85 & Nursing home & Married & $\begin{array}{l}\text { Higher secondary } \\
\text { education }\end{array}$ & Catholic & 19 \\
\hline Beatrice & Woman & 92 & Nursing home & Widowed & $\begin{array}{l}\text { Lower secondary } \\
\text { education }\end{array}$ & Catholic & 21 \\
\hline Alice & Woman & 81 & Nursing home & Married & $\begin{array}{l}\text { Lower secondary } \\
\text { education }\end{array}$ & Catholic & 14 \\
\hline Lillian & Woman & 87 & Nursing home & Widowed & $\begin{array}{l}\text { Higher secondary } \\
\text { education }\end{array}$ & Catholic & 13 \\
\hline Harriet & Woman & 81 & Nursing home & Widowed & $\begin{array}{l}\text { Higher secondary } \\
\text { education }\end{array}$ & Non-religious & / \\
\hline Fred & Man & 90 & Nursing home & Widowed & $\begin{array}{l}\text { Higher secondary } \\
\text { education }\end{array}$ & $\begin{array}{l}\text { Religious without } \\
\text { affiliation to church }\end{array}$ & 13 \\
\hline Raymond & Man & 85 & Private home & Married & Higher education & I & 20 \\
\hline Claude & Man & 87 & Nursing home & Married & Higher education & Other & 23 \\
\hline Leon & Man & 73 & Private home & Married & $\begin{array}{l}\text { Higher secondary } \\
\text { education }\end{array}$ & / & 25 \\
\hline Martin & Man & 87 & Private home & Widowed & Higher education & Christian & 15 \\
\hline
\end{tabular}

Note. ${ }^{\text {a }}$ Potential range $0-30$, higher scores reflect less impairment. 
Table 2. Description of Analysis Steps Following a Phenomenological Reflective Lifeworld Approach.

\begin{tabular}{|c|c|}
\hline Analysis step & Description \\
\hline Familiarization & All transcripts we read and re-read to familiarize with the data and get a sense of the whole text \\
\hline $\begin{array}{l}\text { Identification of } \\
\text { relevant passages }\end{array}$ & $\begin{array}{l}\text { Transcripts were again re-read and all passages relevant to the phenomenon of interest were } \\
\text { marked in bold. The researcher made note of all emerging thoughts in annotations. This allowed } \\
\text { to capture and make explicit the researcher's naive reading and pre-understanding of the data } \\
\text { and phenomenon, and more explicit bridling of this understanding in the following steps }\end{array}$ \\
\hline $\begin{array}{l}\text { Paraphrasing } \\
\text { (code level 1) }\end{array}$ & $\begin{array}{l}\text { All relevant passages were coded on a descriptive level, staying very close to the data and } \\
\text { largely making use of the participants' own words, only slightly paraphrasing and/or } \\
\text { summarizing, e.g., "travelling is meaningful because you see something different, something } \\
\text { new" }\end{array}$ \\
\hline $\begin{array}{l}\text { Meaning units } \\
\text { (code level 2) }\end{array}$ & $\begin{array}{l}\text { Level } 1 \text { codes were reviewed with a focus on the underlying meaning of the expression for the } \\
\text { participant (in contrast to the literal content). Codes reflecting very similar meanings were } \\
\text { grouped under an overarching meaning unit within participants, e.g., "gaining new impressions" }\end{array}$ \\
\hline Meaning clusters & $\begin{array}{l}\text { Meaning units were structured and re-structured, and clustered on a more abstract level across } \\
\text { participants. Meaning clusters were generated by all authors separately and the different } \\
\text { solutions were compared and discussed in team. Diagramming was used to visualize and re- } \\
\text { arrange units and clusters (Finfgeld-Connett, 2014) until consensus was reached }\end{array}$ \\
\hline Constituents & $\begin{array}{l}\text { Meaning clusters were structured and re-structured into even broader constituents that captured } \\
\text { all meaning units and clusters. These were discussed in team until consensus that these } \\
\text { constituents reflected the elements of the experience without which it would not be that } \\
\text { experience }\end{array}$ \\
\hline Essence & $\begin{array}{l}\text { The essence was formulated based on the new whole understanding of the data. Raw transcripts } \\
\text { were re-read to check that the formulated essence and constituents were comprehensive and } \\
\text { grounded in the data }\end{array}$ \\
\hline
\end{tabular}


Table 3. Sample Interview Questions.

\begin{tabular}{|c|c|}
\hline Type & Example \\
\hline Opening question & Can you tell something about how you experience meaning in your life? \\
\hline \multirow[t]{5}{*}{ Follow-up questions } & What is central to you in your life? \\
\hline & When do you think your life wouldn't be meaningful anymore? \\
\hline & Have you had moments where you felt your life was less meaningful? \\
\hline & What makes you feel like getting up in the morning? \\
\hline & What is about that that gives meaning to your life? In what way does that give meaning? \\
\hline \multirow{6}{*}{$\begin{array}{l}\text { Clarifying/deepening } \\
\text { questions }\end{array}$} & Could you tell something more about how that made you feel? \\
\hline & What exactly do you mean by ...? \\
\hline & How was that experience for you? \\
\hline & What did you think during that moment? \\
\hline & That is very helpful, could you explain that some more? \\
\hline & If you think back about that moment, how does that make you feel? \\
\hline \multirow{3}{*}{$\begin{array}{l}\text { Questions adjusted for } \\
\text { participants with stronger } \\
\text { cognitive challenges } \\
\text { (e.g., yes-no format) }\end{array}$} & Do you like to get up in the morning? (...) Why is that? \\
\hline & Are you glad to be still alive? (...) What is that makes you say that? \\
\hline & Would you say that that is something meaningful to you, or is just fun? \\
\hline
\end{tabular}

Note. Sample questions were formulated to assist the interviewer but these were not used as a fixed question list. 


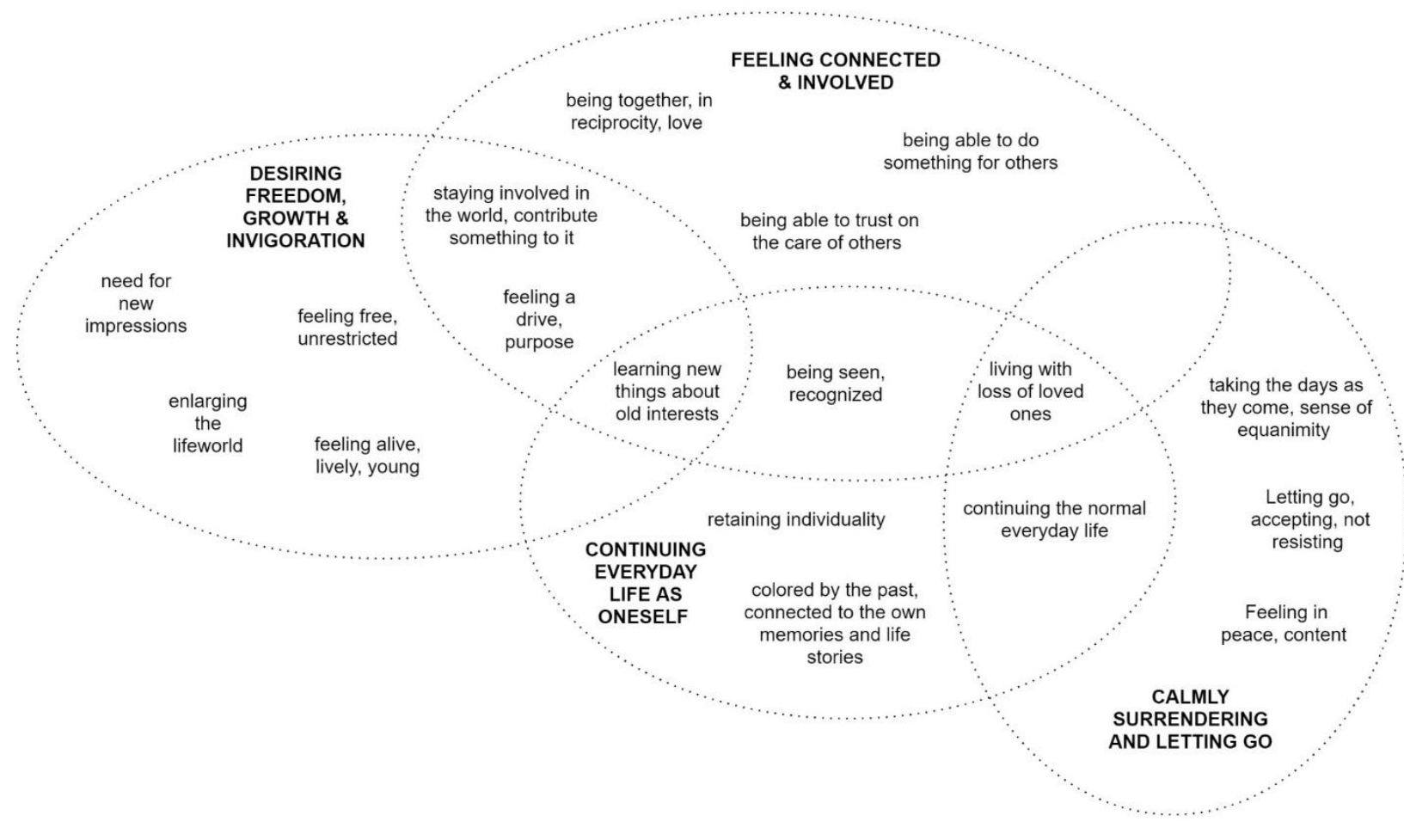

Figure 1. Representation of the Four Intertwined Constituents of the Experience of Meaning in Life for Participants. 